Research Article

\title{
Plastic Failure Analysis of Roadway Floor Surrounding Rocks Based on Unified Strength Theory
}

\author{
Wenxiang Zheng $\mathbb{D}^{1}{ }^{1}$ Qingwei Bu, ${ }^{1}$ and Yaoqing $\mathrm{Hu}^{2}$ \\ ${ }^{1}$ Institute of Mining and Coal, Inner Mongolia University of Science and Technology, Baotou, Inner Mongolia 014010, China \\ ${ }^{2}$ Institute of Mining Technology, Taiyuan University of Technology, Taiyuan, Shanxi 030024, China \\ Correspondence should be addressed to Wenxiang Zheng; shxizwxwxh@imust.edu.cn
}

Received 16 April 2018; Revised 8 June 2018; Accepted 27 June 2018; Published 26 July 2018

Academic Editor: Hang Lin

Copyright (c) 2018 Wenxiang Zheng et al. This is an open access article distributed under the Creative Commons Attribution License, which permits unrestricted use, distribution, and reproduction in any medium, provided the original work is properly cited.

\begin{abstract}
Taking the whole surrounding rock of an excavation roadway as the research object, the elastoplastic failure mechanics analysis of the surrounding rock body of the excavated roadway under three-directional in situ stresses is carried out by using the knowledge of generalized plane strain problems and unified strength theory, and the equations are derived for the elasticplastic zone stress together with the plastic fracture range of the roadway floor surrounding rock under three-directional in situ stresses. At the same time, by means of the conclusion of mechanical analysis and the results of in situ detection of in situ stress in the Changcun mining area, the stability of the roadway floor surrounding rock was analyzed. The analysis reveals the influence on the stability of the roadway floor surrounding rock between the spatial relationship with the different in situ stresses and the roadway layout; meanwhile, it calculates the range of the plastic failure zone and the stress value of the \#1 roadway floor in the S6 mining area of Changcun mine, which provides a reliable theoretical mechanical reference for research on roadway floor heave control technology.
\end{abstract}

\section{Introduction}

Generally, the single shear strength criterion is used for the elastic-plastic mechanics solution of roadway surrounding rocks, such as the Mohr-Coulomb criterion or the HookBrown criterion [1-5]. Although the elastic-plastic failure of the roadway surrounding rocks can be considered as a plane strain problem, in the field engineering practice, the roadway surrounding rock is mostly in the triaxial compression state because of the distribution of residual stresses, the hinge of the fractured rock, and the existence of the supporting structure [6-10]. Owing to the single shear strength criterion, which considers the maximum principal stress and the minimum principal stress and completely neglects the influence of the intermediate principal stress, there is a great difference between the deformation and the actual situation of the surrounding rock of the plastic zone; in the mechanical analysis, the stress on the roadway section is only considered and the effect of axial stress is ignored [11-16]. Recently, many researchers have focused on studying the influence of the roadway axial principal stress to the plastic analysis and timedependent change in the plastic zone of the deep circular roadway and hope the results will fit the specific reality better. For example, Zhao et al. [17-19] studied complex elastoviscoplastic behaviors of rock subjected to triaxial stress state and proposed a new EVP creep model to study timedependent change in the plastic zone. In 1985, Yu et al. $[20,21]$ put forward a unified strength theory and a double shear strength theory based on the concept of double shear. Under the condition of hydrostatic pressure, the elasticplastic distribution of the circular roadway obtained by the unified strength theory is analyzed. Compared with the Mohr-Coulomb strength theory, the parameters of the roadway axial stress and strength theory have an impact on the roadway surrounding rock plastic zone radius, stress distribution, and radial displacement [22-25]. This paper utilizes the uniform strength theory as the criteria of plastic failure of roadway surrounding rock and analyzes the plastic mechanics 


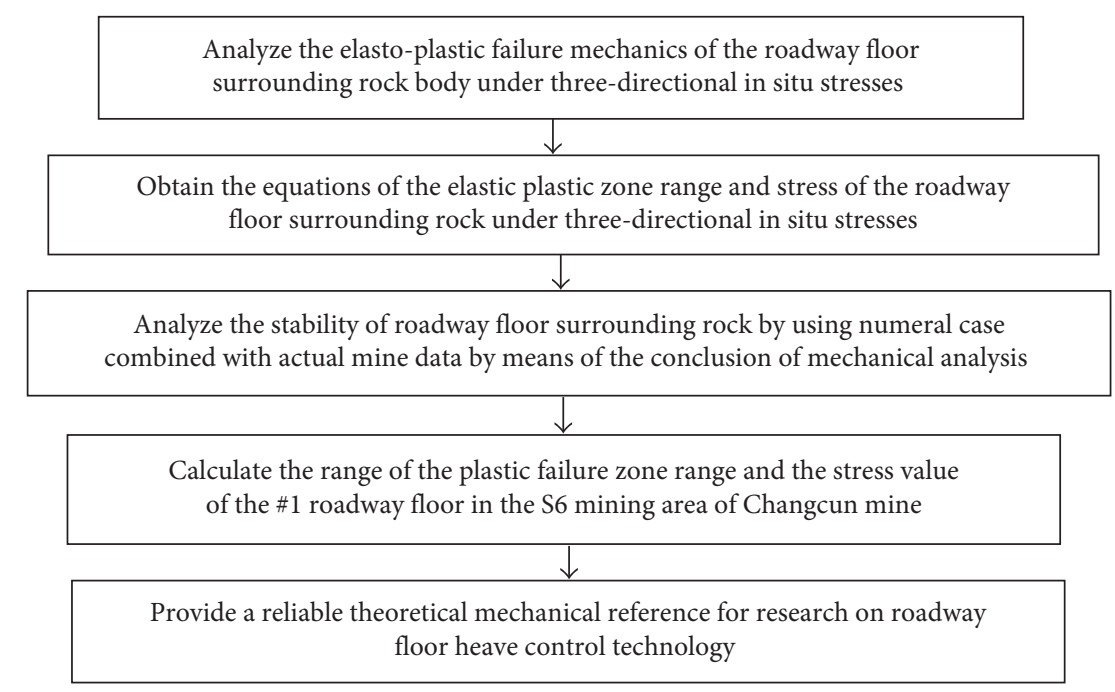

FIgURE 1: The flowchart for the research.

of the surrounding rock of a circular roadway under the triaxial stress condition $[26,27]$. Figure 1 is a flowchart for the research.

\section{The Mechanical Analysis of Plastic Failure Zone Range and Stress of Roadway Floor Surrounding Rock under Three- Directional In Situ Stresses}

Assuming that the compressive stress is positive, while the tensile stress is negative, the unified strength theory can be expressed as

$$
\begin{gathered}
F=\lambda \sigma_{1}-\frac{e \sigma_{2}+\sigma_{3}}{1+e}=\sigma_{t}, \quad\left(\sigma_{2} \leq \frac{\lambda \sigma_{1}+\sigma_{3}}{1+\lambda}\right), \\
F^{\prime}=\frac{\lambda\left(\sigma_{1}+e \sigma_{2}\right)}{1+e}-\sigma_{3}=\sigma_{t}, \quad\left(\sigma_{2} \geq \frac{\lambda \sigma_{1}+\sigma_{3}}{1+\lambda}\right),
\end{gathered}
$$

where $\sigma_{1}$ is the maximum principal stress, $\sigma_{2}$ is the intermediate principal stress, $\sigma_{3}$ is the minimum principal stress, $e$ is the effect of the intermediate principal stress and the normal stress acting on the failure surface of the material, $\lambda$ is the tension and compression ratio of the material, and $\sigma_{t}$ is the uniaxial tensile strength of the material [28-30].

For rock materials, if (1) and (2) are represented by the principal stress, rock cohesion $C$, and rock internal friction angle $\varphi$, they can be written as

$$
\begin{array}{r}
F=\sigma_{1}(1-\sin \varphi)-\frac{e \sigma_{2}+\sigma_{3}}{1+e}(1+\sin \varphi)=2 C \cos \varphi, \\
\sigma_{2} \leq \frac{\sigma_{1}+\sigma_{3}}{2}-\frac{\sigma_{1}-\sigma_{3}}{2} \sin \varphi, \\
F^{\prime}=\frac{\sigma_{1}+e \sigma_{2}}{1+e}(1-\sin \varphi)-\sigma_{3}(1+\sin \varphi)=2 C \cos \varphi, \\
\sigma_{2} \geq \frac{\sigma_{1}+\sigma_{3}}{2}-\frac{\sigma_{1}-\sigma_{3}}{2} \sin \varphi .
\end{array}
$$

2.1. The Solution of Stress Equation in Plastic Failure Zone of Roadway Floor Surrounding Rock Based on Unified Strength Theory. Assuming that the strain of the plastic zone surrounding rock mass satisfies $\varepsilon_{V}=0$, the relationship among radial stress $\sigma_{r}^{p}$, tangential stress $\sigma_{\theta}^{p}$, and axial stress $\sigma_{z}^{p}$ in the plastic zone can be described by

$$
\sigma_{z}^{p}=\frac{1}{2}\left(\sigma_{r}^{p}+\sigma_{\theta}^{p}\right)
$$

In the roadway surrounding rock mass around, tangential stress $\sigma_{\theta}^{p}$ is the largest and radial stress $\sigma_{r}^{p}$ is the smallest; according to the brief description of the theory of uniform strength, we can see that if the three principal stresses in the plastic zone satisfy $\sigma_{2} \geq\left(\left(\sigma_{1}+\sigma_{3}\right) / 2\right)-$ $\left(\left(\sigma_{1}-\sigma_{3}\right) / 2\right) \sin \varphi$, then (5) is established:

$$
\frac{\sigma_{\theta}^{p}+e \sigma_{z}^{p}}{1+e}(1-\sin \varphi)-\sigma_{r}^{p}(1+\sin \varphi)=2 C \cos \varphi .
$$

Substituting (4) into (5):

$$
\sigma_{\theta}^{p}=K_{p} \sigma_{r}^{p}+K_{c}
$$

where

$$
\begin{aligned}
& K_{p}=\frac{2+2 \sin \varphi+3 e \sin \varphi+e}{(2+e)(1-\sin \varphi)}, \\
& K_{c}=\frac{4 C(1+e) \cos \varphi}{(2+e)(1-\sin \varphi)} .
\end{aligned}
$$

In the plastic failure zone, when the roadway surrounding rock is in the ultimate equilibrium stress state, the stress of the plastic zone is basically unrelated with the stress of the original rock. The equivalent floor shape is an axisymmetric roadway, so the stress distribution of the plastic fracture zone of the surrounding rock has an axisymmetric shape. When the body force is not taken into account, the axisymmetric equilibrium equation for the plane strain problem of the plastic zone is expressed as 


$$
\begin{aligned}
r \frac{d \sigma_{r}^{p}}{d r}+\sigma_{r}^{p}-\sigma_{\theta}^{p} & =0, \\
\tau_{r \theta}^{p} & =0 .
\end{aligned}
$$

Combined with (6), it can be rewritten as

$$
\frac{d \sigma_{r}^{p}}{\left(\sigma_{r}^{p}+\left(K_{c} /\left(K_{p}-1\right)\right)\right)}=\frac{\left(K_{p}-1\right)}{r} d r .
$$

Using a differential equation, (10) is derived:

$$
\ln \left(\sigma_{r}^{p}+\frac{K_{c}}{\left(K_{p}-1\right)}\right)=\left(K_{p}-1\right) \ln r+Q .
$$

According to the boundary condition $r=R_{0}, \sigma_{r}^{p}=P_{i}\left(P_{i}\right.$ is the support force):

$$
Q=\frac{1}{K_{p}-1} \ln \left(P_{i}\left(K_{p}-1\right)+K_{c}\right)-\ln R_{0} .
$$

Hence, the following is obtained:

$$
\begin{aligned}
\sigma_{r}^{p} & =\left(P_{i}+\frac{K_{c}}{\left(K_{p}-1\right)}\right)\left(\frac{r}{R_{0}}\right)^{K_{p}-1}-\frac{K_{c}}{\left(K_{p}-1\right)}, \\
\sigma_{\theta}^{p} & =K_{p}\left(P_{i}+\frac{K_{c}}{\left(K_{p}-1\right)}\right)\left(\frac{r}{R_{0}}\right)^{K_{p}-1}-\frac{K_{c}}{\left(K_{p}-1\right)}, \\
\sigma_{y 1}^{p} & =\left(\frac{K_{p}+1}{2}\right)\left(P_{i}+\frac{K_{c}}{\left(K_{p}-1\right)}\right)\left(\frac{r}{R_{0}}\right)^{K_{p}-1}-\frac{K_{c}}{\left(K_{p}-1\right)}, \\
\tau_{r \theta}^{p} & =0 .
\end{aligned}
$$

2.2. The Solution of Plastic Failure Zone Range of Roadway Floor Surrounding Rock. The calculation form of the plastic fractured zone $S$ is as follows:

$$
S=r_{p}+f(\theta) .
$$

In the $r=S$ position, to facilitate the calculation of the above formula, $r^{-2}, r^{-4}, r^{K_{p}-1}$, and $r^{K_{p}+1}$ need to be simplified. Therefore, expanding the polynomial and omitting the all after three items of polynomials, they are expressed as

$$
\begin{aligned}
r^{-2} & =S^{-2}=r_{p}^{-2}-2 f(\theta) r_{p}^{-3}, \\
r^{-4} & =S^{-4}=r_{p}^{-4}-4 f(\theta) r_{p}^{-5}, \\
r^{K_{p}+1} & =S^{K_{p}+1}=r_{p}^{K_{p}+1}+\left(K_{p}+1\right) f(\theta) r_{p}^{K_{p}}, \\
r^{K_{p}-1} & =S^{K_{p}-1}=r_{p}^{K_{p}-1}+\left(K_{p}-1\right) f(\theta) r_{p}^{K_{p}-2} .
\end{aligned}
$$

The stress equations for the plastic fracture zone and the elastic zone of the roadway floor surrounding rock under inhomogeneous stress can be described by (14).

The stress equation of the plastic fracture zone is

$$
\begin{aligned}
\sigma_{r}^{p}= & \left(P_{i}+\frac{K_{c}}{\left(K_{p}-1\right)}\right)\left(\frac{1}{R_{0}}\right)^{K_{p}-1} \\
& \cdot\left(r_{p}^{K_{p}-1}+\left(K_{p}-1\right) f(\theta) r_{p}^{K_{p}-2}\right)-\frac{K_{c}}{\left(K_{p}-1\right)},
\end{aligned}
$$

$$
\begin{aligned}
\sigma_{\theta}^{p}= & K_{p}\left(P_{i}+\frac{K_{c}}{\left(K_{p}-1\right)}\right)\left(\frac{1}{R_{0}}\right)^{K_{p}-1} \\
& \cdot\left(r_{p}^{K_{p}-1}+\left(K_{p}-1\right) f(\theta) r_{p}^{K_{p}-2}\right)-\frac{K_{c}}{\left(K_{p}-1\right)}, \\
\sigma_{y}^{p}= & \left(\frac{K_{p}+1}{2}\right)\left(P_{i}+\frac{K_{c}}{\left(K_{p}-1\right)}\right)\left(\frac{1}{R_{0}}\right)^{K_{p}-1} \\
& \cdot\left(r_{p}^{K_{p}-1}+\left(K_{p}-1\right) f(\theta) r_{p}^{K_{p}-2}\right)-\frac{K_{c}}{\left(K_{p}-1\right)}, \\
\tau_{r \theta}^{p}= & 0 .
\end{aligned}
$$

The stress equations of the elastic zone is

$$
\begin{aligned}
\sigma_{r}^{e}= & \frac{P_{x}+P_{z}}{2}\left[1-a\left(r_{p}^{-2}-2 f(\theta) r_{p}^{-3}\right)\right] \\
& +\frac{P_{x}-P_{z}}{2} \cos (2 \theta)\left[1-2 b\left(r_{p}^{-2}-2 f(\theta) r_{p}^{-3}\right)\right. \\
& \left.+c\left(r_{p}^{-4}-4 f(\theta) r_{p}^{-5}\right)\right], \\
\sigma_{\theta}^{e}= & \frac{P_{x}+P_{z}}{2}\left[1+a\left(r_{p}^{-2}-2 f(\theta) r_{p}^{-3}\right)\right] \\
& -\frac{P_{x}-P_{z}}{2} \cos (2 \theta)\left[1+c\left(r_{p}^{-4}-4 f(\theta) r_{p}^{-5}\right)\right], \\
\sigma_{y}^{e}= & P_{y}-\mu b\left(P_{x}-P_{z}\right) \cos (2 \theta)\left(r_{p}^{-2}-2 f(\theta) r_{p}^{-3}\right), \\
\tau_{r \theta}^{e}= & \tau_{\theta r}^{e}=-\frac{P_{x}-P_{z}}{2} \sin (2 \theta)\left[1+b\left(r_{p}^{-2}-2 f(\theta) r_{p}^{-3}\right)\right. \\
& \left.-c\left(r_{p}^{-4}-4 f(\theta) r_{p}^{-5}\right)\right] .
\end{aligned}
$$

The tangential stress and radial stress equations are analyzed in light of the equality of stress continuous conditions, equal stress, and are represented by the formulas 


$$
\begin{aligned}
N\left(\frac{1}{R_{0}}\right)^{K_{p}-1} r_{p}^{K_{p}-1}-\frac{K_{c}}{\left(K_{p}-1\right)}=\frac{P_{x}+P_{z}}{2}\left(1-a r_{p}^{-2}\right) \\
K_{p} N\left(\frac{1}{R_{0}}\right)^{K_{p}-1} r_{p}^{K_{p}-1}-\frac{K_{c}}{\left(K_{p}-1\right)}=\frac{P_{x}+P_{z}}{2}\left(1+a r_{p}^{-2}\right) \\
N\left(\frac{1}{R_{0}}\right)^{K_{p}-1}\left(\left(K_{p}-1\right) f(\theta) r_{p}^{K_{p}-2}\right) \\
=\frac{P_{x}+P_{z}}{2}\left(2 f(\theta) a r_{p}^{-3}\right)+\frac{P_{x}-P_{z}}{2} \cos (2 \theta) \\
\cdot\left[1-2 b\left(r_{p}^{-2}-2 f(\theta) r_{p}^{-3}\right)+c\left(r_{p}^{-4}-4 f(\theta) r_{p}^{-5}\right)\right] \\
K_{p} N\left(\frac{1}{R_{0}}\right)^{K_{p}^{-1}}\left(\left(K_{p}-1\right) f(\theta) r_{p}^{K_{p}-2}\right) \\
=\frac{P_{x}+P_{z}}{2}\left(-2 f(\theta) a r_{p}^{-3}\right)-\frac{P_{x}-P_{z}}{2} \cos (2 \theta) \\
\cdot\left[1+c\left(r_{p}^{-4}-4 f(\theta) r_{p}^{-5}\right)\right],
\end{aligned}
$$

where $N=\left(P_{i}+\left(K_{c} /\left(K_{p}-1\right)\right)\right)$.

When the boundary position is $\left.\tau_{r \theta}^{e}\right|_{S}=\left.\tau_{\theta r}^{e}\right|_{S}=\left.\tau_{r \theta}^{p}\right|_{S}=$ $\left.\tau_{\theta r}^{p}\right|_{S}=0$,

$$
H=1+b\left(r_{p}^{-2}-2 f(\theta) r_{p}^{-3}\right)-c\left(r_{p}^{-4}-4 f(\theta) r_{p}^{-5}\right)=0 .
$$

According to (18), previous formulas are rewritten as

$$
\begin{aligned}
& N\left(\frac{1}{R_{0}}\right)^{K_{p}-1}\left(\left(K_{p}-1\right) f(\theta) r_{p}^{K_{p}-2}\right) \\
&= \frac{P_{x}+P_{z}}{2}\left(2 f(\theta) a r_{p}^{-3}\right)+\frac{P_{x}-P_{z}}{2} \cos (2 \theta) \\
& \cdot\left(2-H-b\left(r_{p}^{-2}-2 f(\theta) r_{p}^{-3}\right)\right), \\
& K_{p} N\left(\frac{1}{R_{0}}\right)^{K_{p}-1}\left(\left(K_{p}-1\right) f(\theta) r_{p}^{K_{p}-2}\right) \\
&=\frac{P_{x}+P_{z}}{2}\left(-2 f(\theta) a r_{p}^{-3}\right)-\frac{P_{x}-P_{z}}{2} \cos (2 \theta) \\
& \cdot\left(2-H+b\left(r_{p}^{-2}-2 f(\theta) r_{p}^{-3}\right)\right) .
\end{aligned}
$$
follows:

$$
\begin{gathered}
\left(K_{p}-1\right) \frac{\left(\left(P_{x}+P_{z}\right)+2\left(K_{c} /\left(K_{p}-1\right)\right)\right)}{\left(K_{p}+1\right)}\left(\left(K_{p}-1\right) f(\theta)\right) \\
=-2 f(\theta)\left(P_{x}+P_{z}\right) \frac{\left(\left(P_{x}+P_{z}\right)\left(K_{p}-1\right)+2 K_{c}\right)}{\left(P_{x}+P_{z}\right)\left(K_{p}+1\right)} \\
-\left(P_{x}-P_{z}\right) \cos (2 \theta)(2-2 H) r_{p}, \\
f(\theta)=\frac{2\left(P_{z}-P_{x}\right) \cos (2 \theta) r_{p}}{\left(\left(P_{x}+P_{z}\right)+2\left(K_{c} /\left(K_{p}-1\right)\right)\right)\left(K_{p}-1\right)},
\end{gathered}
$$

where $r_{p}=R_{0}\left[\left(\left(P_{x}+P_{z}\right)+2\left(K_{c} /\left(K_{p}-1\right)\right)\right) /\left(K_{p}+1\right) N\right]^{1 /\left(K_{p}-1\right)}$, and $N, K_{p}$, and $K_{c}$ are the same as above.

The equation of plastic fracture zone range $S$ of roadway floor surrounding rock is expressed as (22) according to (13):

$$
\begin{aligned}
S= & {\left[\frac{\left(\left(P_{x}+P_{z}\right)+2\left(K_{c} /\left(K_{p}-1\right)\right)\right)}{\left(K_{p}+1\right)\left(P_{i}+\left(K_{c} /\left(K_{p}-1\right)\right)\right)}\right]^{1 /\left(K_{p}-1\right)} R_{0} } \\
& -\frac{2\left(P_{x}-P_{z}\right) \cos (2 \theta)}{\left(\left(P_{x}+P_{z}\right)+2\left(K_{c} /\left(K_{p}-1\right)\right)\right)\left(K_{p}-1\right)} \\
& \cdot\left[\frac{\left(\left(P_{x}+P_{z}\right)+2\left(K_{c} /\left(K_{p}-1\right)\right)\right)}{\left(K_{p}+1\right)\left(P_{i}+\left(K_{c} /\left(K_{p}-1\right)\right)\right)}\right]^{1 /\left(K_{p}-1\right)} R_{0} .
\end{aligned}
$$

When the intermediate principal stress is neglected (i.e., $e=0$ ), the equation is consistent with the Rubinite equation; when $P_{x}=P_{z}$, the equation is consistent with the Castner equation.

According to the unified strength theory, the equations of plastic fracture zone range and stress of roadway floor surrounding rock are derived under three-directional in situ stresses, the influence of middle principal stress is considered, and the elastoplastic plane strain problem of roadway floor surrounding rock is studied by using the previous single shear strength criterion (such as Mohr-Coulomb criterion and Hook-Brown criterion), so that it is better suited to the practice. But there are the following shortcomings. It still takes the prototype roadway as the research object, and assumes that the surrounding rock is a uniform continuous medium, and does not consider the discontinuity of the surrounding rock and the shear effect of the surrounding rock after entering the plastic state. Many of the formulas obtained are less verified in the field. There is still a certain error in the result.

\section{The Stability Numeral Case Analysis of Roadway Floor Surrounding Rock}

Due to the roadway layout and the limitation of its use, it is inevitable that the roadway's spatial position and the threedimensional principal stress of the in situ stress form a certain spatial relationship. The three-dimensional principal stress magnitude and orientation of the underground rock strata can be obtained by making use of the geodesic technique as well as the known conditions of the original rock stress. Moreover, the stability of the roadway floor is analyzed according to the different in situ stress environments and the spatial relationship of the roadway layout. Figure 2 is the numerical model of the roadway in a random direction.

The following are the assumed initial conditions: the three-dimensional principal stress of the in situ stress are $P_{0 x}=P_{0 y}=P_{0 z}=10 \mathrm{~Pa}$, the roadway rock mass cohesion is $C=1 \mathrm{MPa}$, the internal friction angle is $\varphi=30^{\circ}$, the unified strength theory coefficient is $e=0$, the range of the plastic failure zone of roadway surrounding rock is $S$, the support resistance in the unsupported state is $0 \mathrm{MPa}$, and the radius of the equivalent circular roadway is $R_{0}=2.5 \mathrm{~m}$. 
When the initial in situ stress satisfies $P_{0 x}>P_{0 y}=P_{0 z}$, $P_{0 x}=20 \mathrm{MPa}$ and $\beta=0^{\circ}$, the three-dimensional stress state of roadway surrounding rock, the plastic failure zone, and the plastic failure zone boundary stress distribution with the increase of $\alpha$ are as shown in Figure 3.

It can be seen from Figure 3 that the horizontal coordinate of the roadway section and the horizontal stress of the in situ stress with the change of $\alpha$, and the stress state of the vertical stress $P_{z}$ do not change. However, a stress state transition between the horizontal stress component $P_{x}$ of the roadway section and the axial horizontal stress component $P_{y}$ is produced, which causes a marked stress redistribution of the roadway floor surrounding rock, and the changes of the floor surrounding rock is obvious in the plasticity. When the initial in situ stress satisfies $P_{0 x}>P_{0 y}=P_{0 z}$, the horizontal stress component $P_{x}$ of the roadway section gradually decreases and converts into $P_{0 y}$, and the axial horizontal stress component $P_{y}$ of the roadway gradually increases and converts into $P_{0 x}$ with the increase of $\alpha$. The plastic fracture distribution of the roadway floor is significantly reduced, while the plastic fracture deformation of the both sides of the surrounding rock is slightly increased. It is shown that a reduction of the horizontal stress component $P_{x}$ of the roadway section and an increase of the axial horizontal principal stress component $P_{y}$ of the roadway have the gain effect to the stability of the roadway floor surrounding rock. If $\alpha$ is close to $0^{\circ}$, the horizontal stress component $P_{x}$ of the roadway section is basic approaches the maximum stress component $P_{0 x}$ of the in situ stress component; at this time, the plastic failure distribution of the floor rock mass is the largest, and the stress distribution of the surrounding rock is the most severe. Moreover, the most difficult to control is the floor surrounding rock. Therefore, it is concluded that the horizontal stress component of the roadway section should be avoided in accordance with the maximum stress component in the threedimensional stress state, and the support intensity of the roadway floor should be increased when the initial vertical stress is greater than the maximum vertical stress, so as to guarantee the safety and stability of the roadway surrounding rock.

When the initial in situ stress satisfies $P_{0 x}>P_{0 y}=P_{0 z}$, $P_{0 x}=20 \mathrm{MPa}$ and $\alpha=0^{\circ}$, the changes in the threedimensional stress state of roadway surrounding rock, the plastic failure zone, and the plastic failure zone boundary stress distribution as $\beta$ increases are as shown in Figure 4.

It can be seen from Figure 4 that the change of the inclination angle $\beta$ between the roadway's axis and the horizontal plane and the stress state of the horizontal stress component $P_{x}$ of the roadway section do not change; however, a stress state transition between the roadway vertical stress component $P_{z}$ and the roadway axial horizontal stress component $P_{y}$ is produced, which causes a marked stress redistribution on both sides of the roadway surrounding rock, and the changes in both sides of the roadway surrounding rock are obvious in the plasticity. When the initial in situ stress satisfies $P_{0 z}>P_{0 x}=P_{0 y}$, the roadway vertical stress component $P_{z}$ gradually decreases to convert to $P_{0 y}$, and the roadway axial horizontal stress component $P_{y}$ gradually increases to convert to $P_{0 z}$ as $\beta$ increases. Although the destruction of the floor rock is slightly increased, the distribution of plastic fractures in both sides of the roadway surrounding rock is significantly reduced;

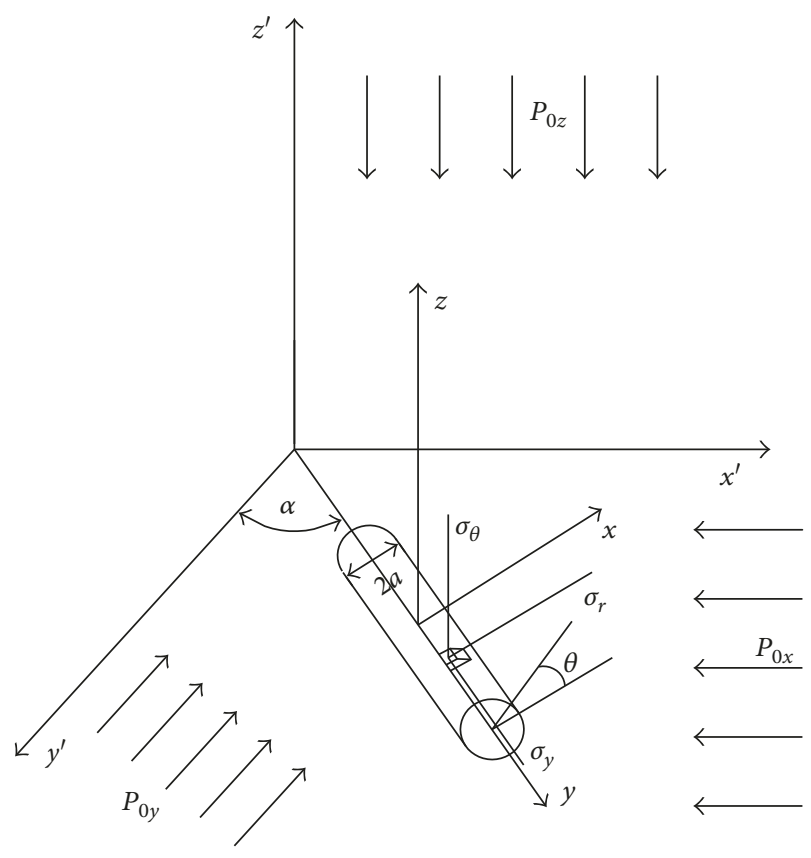

FIgURE 2: The numerical model of the roadway in a random direction.

the advantage is that the span of the roadway floor surrounding rock is obvious reduced. In addition, as the model span decreases, the amount of load, the transverse stress and shear stress in the beam, and the deflection will be significantly reduced; it is beneficial to the stable bearing of the roadway floor surrounding rock. This result indicates that the decrease of the roadway vertical stress component $P_{z}$ and the increase of the roadway horizontal stress component $P_{y}$ make the span of the roadway floor surrounding rock to reduce. This phenomenon presents a gain effect to the stability of roadway floor surrounding rock. If $\beta$ is close to $0^{\circ}$, the vertical stress component $P_{z}$ of the roadway section basically approaches the maximum stress component $P_{0 x}$ of the in situ stress component. Under these conditions, the plasticity failure zone of the floor surrounding rock is slightly reduced, but the span of the roadway floor surrounding rock is increased, which may bring about a drastic change in the stress distribution of floor surrounding rock. Moreover, the floor heave cannot be effectively controlled, and the support structure is unstable due to the increase of the size of the surrounding rock. Therefore, it is also important to pay attention to the three-dimensional stress state of the in situ stress to support the inclined roadway, according to the stress distribution of the surrounding rock and the distribution characteristics of the plastic fracture, and the spatial position relationship of the roadway should be combined to guide the roadway floor heave to ensure the safety and stability of the floor surrounding rock.

\section{The Mechanical Analysis of Plastic Failure Zone Range and Stress of the \#1 Roadway Floor in the S6 Mining Area of Changcun Mine}

The test results of the geomechanics and in situ stresses of the roadway surrounding rock in Changcun mine show 


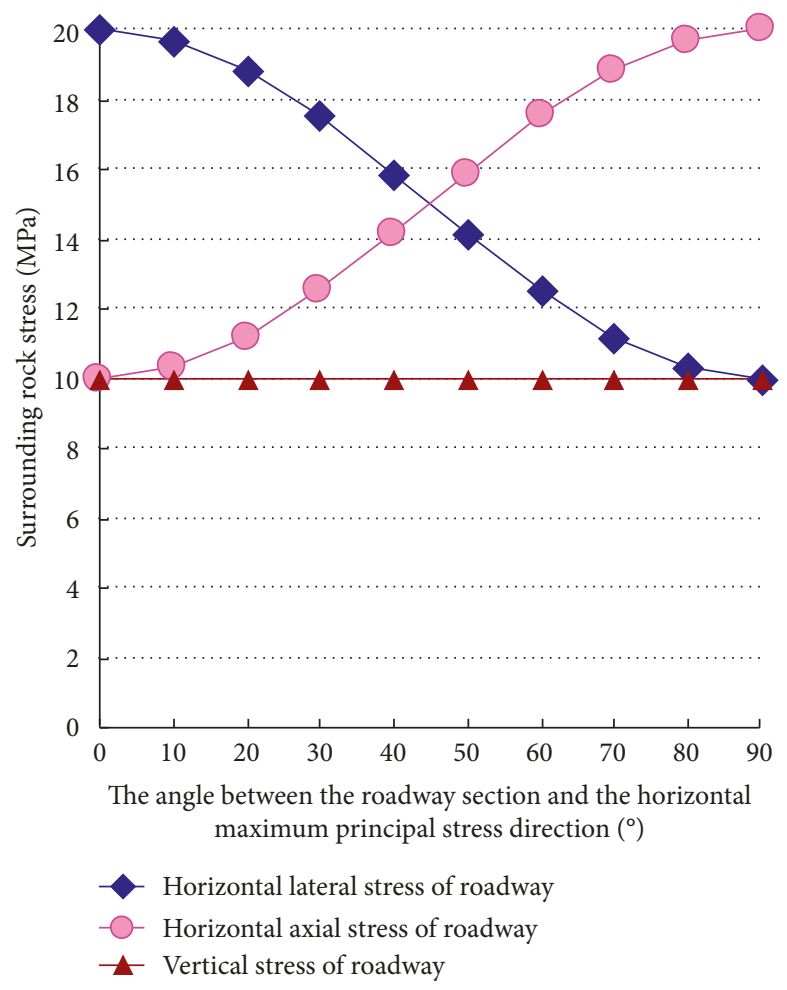

(a)

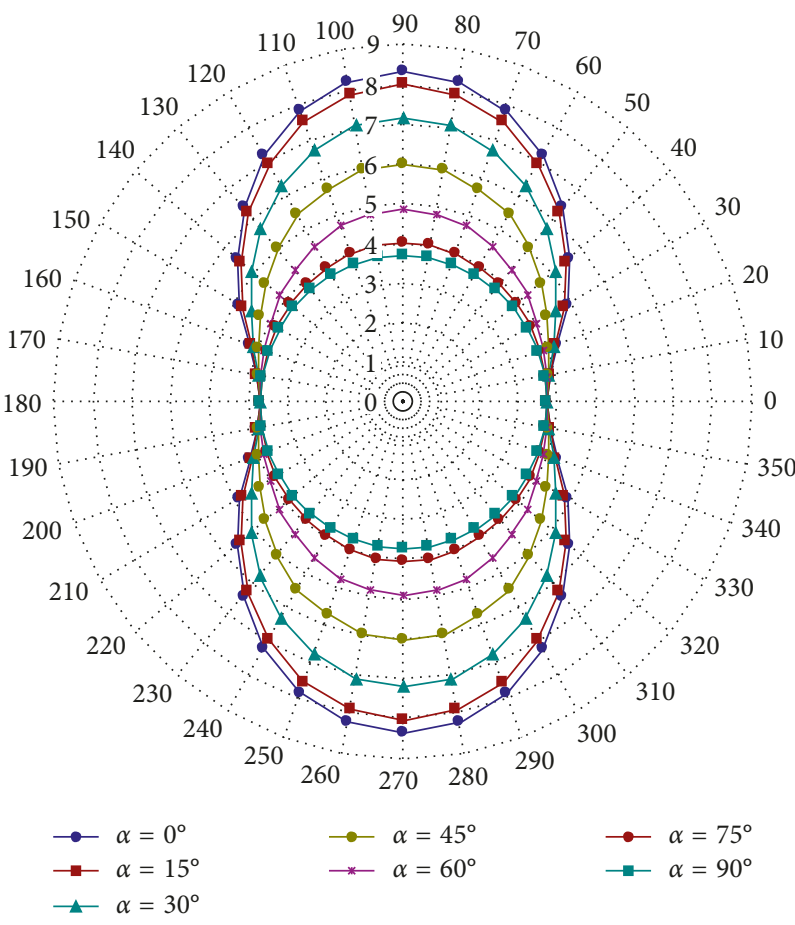

(c)

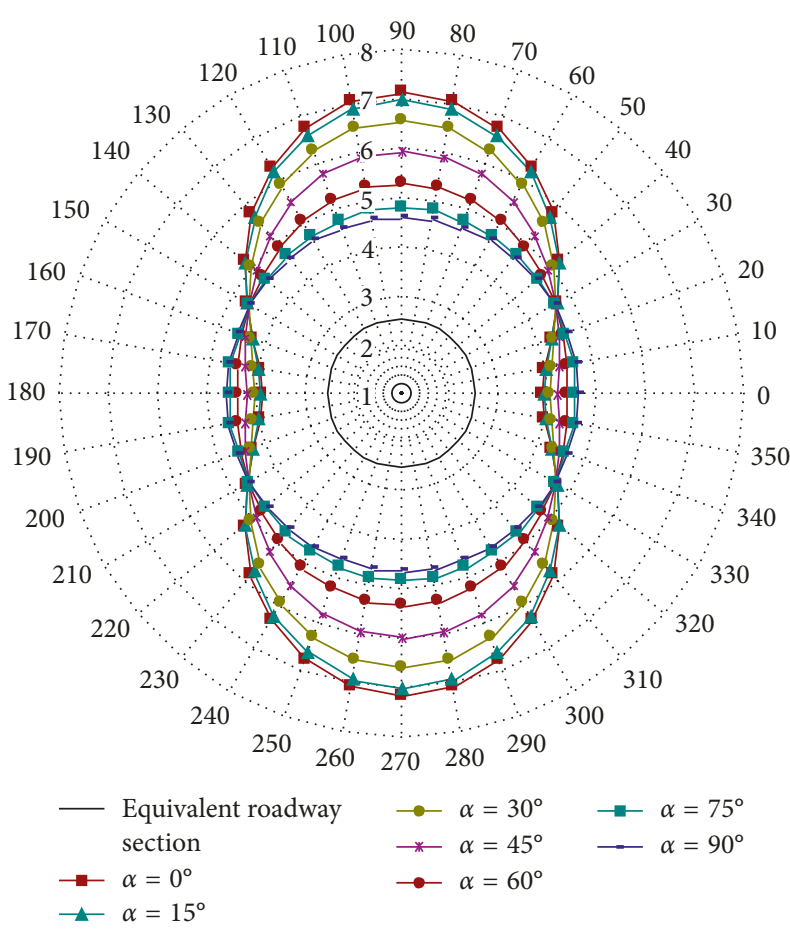

(b)

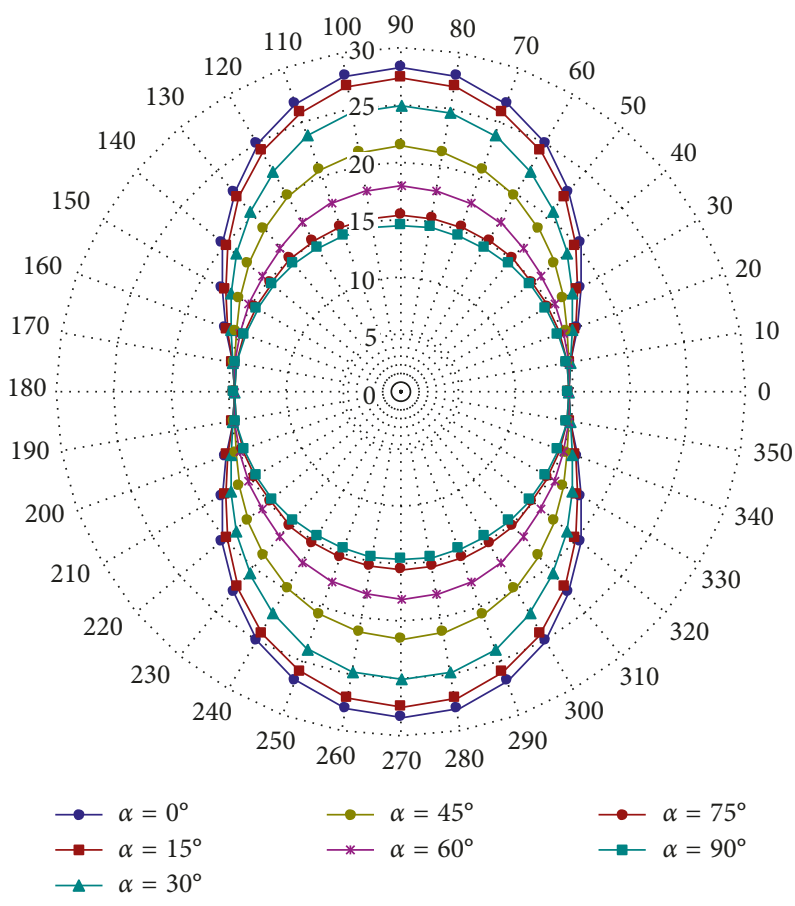

(d)

FIGURE 3: The three-dimensional stress states and change rules of the stress distribution in the surrounding rock plastic zone and plastic zone boundary with the increase of $\alpha$. (a) Three-dimensional stress state change, (b) plastic failure zone distribution changes, (c) plastic failure zone boundary radial stress distribution change, (d) plastic failure zone boundary tangential stress distribution change.

that the three-dimensional principal stress of the in situ stresses are $P_{0 x}=11.31 \mathrm{MPa}, P_{0 y}=5.92 \mathrm{MPa}$, and $P_{0 z}=8.36 \mathrm{MPa}$, the average compressive strength of the surrounding rock mass is $6.77 \mathrm{MPa}$ (cohesion $C=2.2 \mathrm{MPa}$, internal friction angle $\varphi=24^{\circ}$ ), the included angle of the roadway's horizontal plane is $\alpha=6.1^{\circ}$, and the roadway incidence is $\beta=6^{\circ}$. 

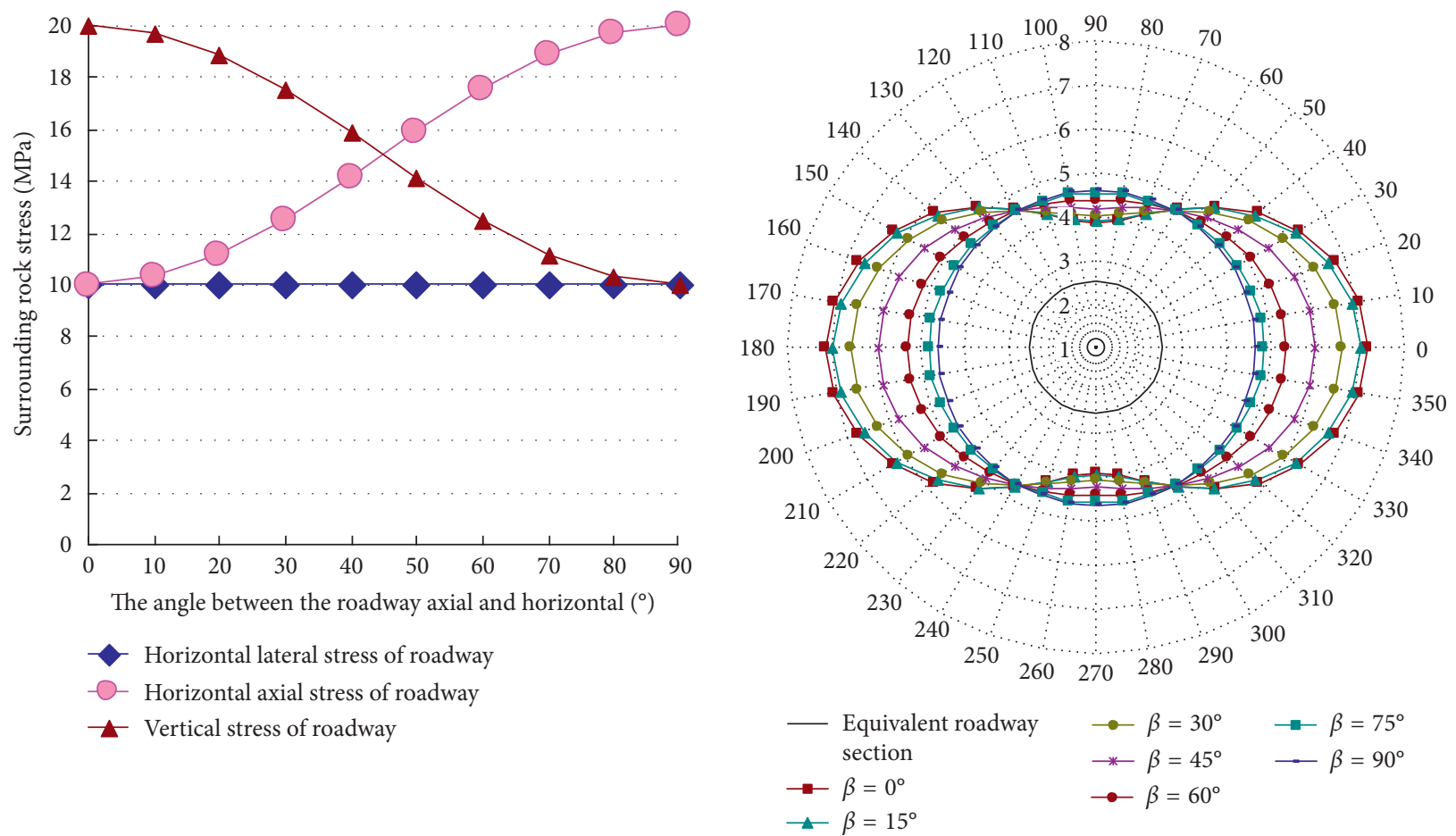

(a)

(b)

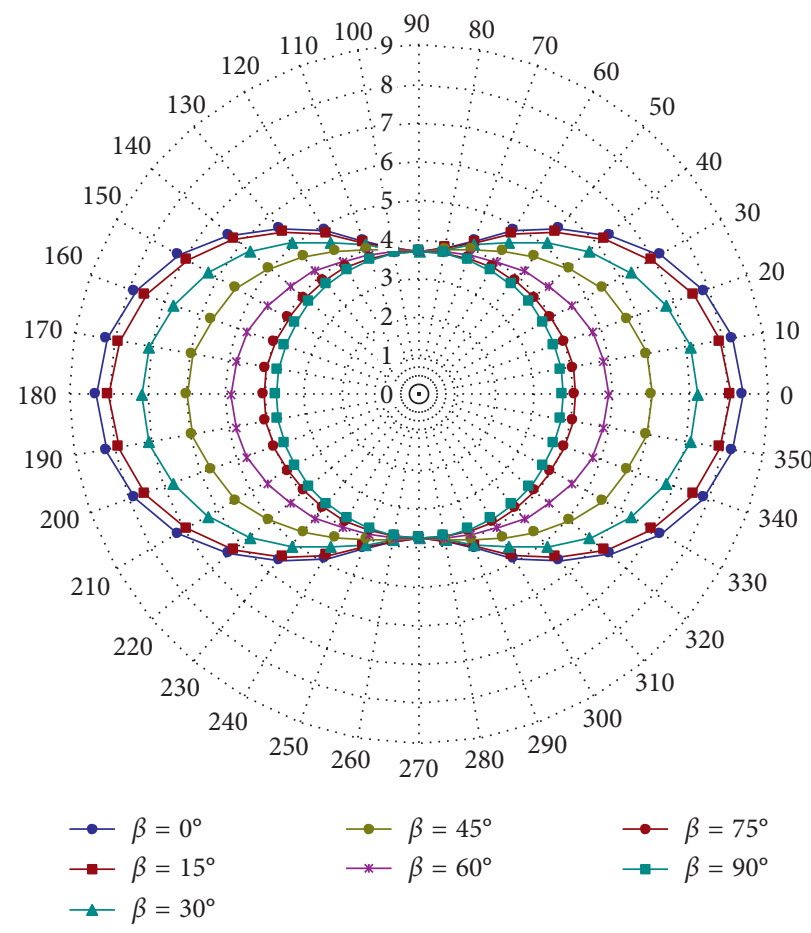

(c)

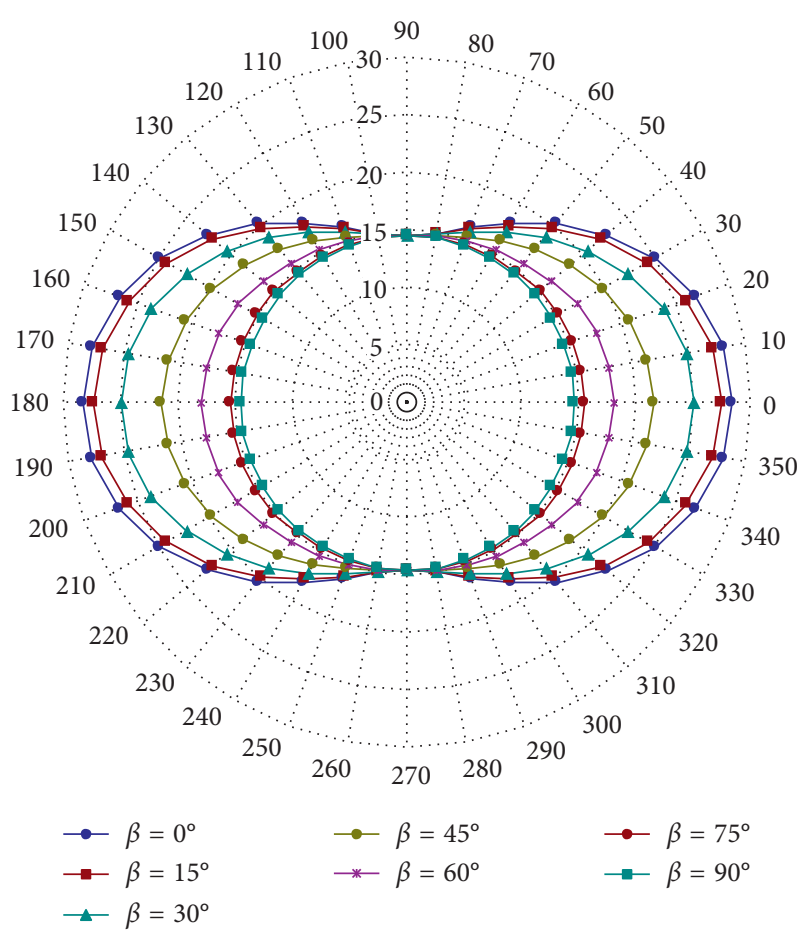

(d)

FIgURE 4: The three-directional stress states and change rules of the stress distribution in the surrounding rock plastic zone and plastic zone boundary with the increase of $\beta$. (a) Three-dimensional stress state change, (b) plastic failure zone distribution changes, (c) plastic failure zone boundary radial stress distribution change, and (d) plastic failure zone boundary tangential stress distribution change.

Further, when the unified strength theory coefficient is $e=0$, destruction of the surrounding rock is the most dangerous. Supposing that the radius of the equivalent circular roadway is $R_{0}=3.05 \mathrm{~m}$, the plastic failure zone range $S$ and the stress values of the floor surrounding rock of the \#1 return airway in the S6 mining area of Changcun mine are calculated according to the previous mechanical analysis. 
4.1. The Primary Rock Stress Calculation of Floor Surrounding Rock

$\left[\begin{array}{lll}P_{x} & P_{x y} & P_{z z} \\ P_{y x} & P_{y} & P_{y z} \\ P_{z x} & P_{z y} & P_{z}\end{array}\right]=\left[\begin{array}{ccc}11.31 \cos ^{2} 6.1^{\circ}+5.92 \sin ^{2} 6.1^{\circ} & (11.31-5.92) \cos 6.1^{\circ} \sin 6.1^{\circ} \cos 6^{\circ} & (11.31-5.92) \cos 6.1^{\circ} \sin 6.1^{\circ} \sin 6^{\circ} \\ (11.31-5.92) \cos 6.1^{\circ} \sin 6.1^{\circ} \cos 6^{\circ} & \left(11.31 \sin ^{2} 6.1^{\circ}+5.92 \cos ^{2} 6.1^{\circ}\right) \cos ^{2} 6^{\circ}+8.63 \sin ^{2} 6^{\circ} & \left(11.31 \sin ^{2} 6.1^{\circ}+5.92 \cos ^{2} 6.1^{\circ}-8.63\right) \cos ^{\circ} \sin ^{\circ} \\ (11.31-5.92) \cos 6.1^{\circ} \sin 6.1^{\circ} \sin 6^{\circ} & \left(11.31 \sin ^{2} 6.1^{\circ}+5.92 \cos ^{2} 6.1^{\circ}-8.63\right) \cos 6^{\circ} \sin 6^{\circ} & \left(13.19 \sin ^{2} 6.1^{\circ}+5.92 \cos ^{2} 6.1^{\circ}\right) \sin ^{2} 6^{\circ}+8.63 \cos ^{2} 6^{\circ}\end{array}\right]$

By calculating, the primary rock stresses are

$$
\begin{aligned}
& P_{x}=11.25 \mathrm{MPa}, \\
& P_{v}=6.01 \mathrm{MPa}, \\
& P_{z}=8.60 \mathrm{MPa} .
\end{aligned}
$$

4.2. The Solutions of Plastic Failure Zone Range S and Stress Value of Floor Surrounding Rock. Here,

$$
\begin{aligned}
K_{c} & =\frac{2 \times 2.2 \cos 24^{\circ}}{\left(1-\sin 24^{\circ}\right)}=6.77, \\
K_{p} & =\frac{1+\sin 24^{\circ}}{\left(1-\sin 24^{\circ}\right)}=2.37, \\
N & =\frac{6.77}{(2.37-1)}=4.94, \\
r_{p} & =3.05 \times\left[\frac{((11.25+8.60)+2 \times(6.77 /(2.37-1)))}{(2.37+1) \times 4.94}\right]^{1 /(2.37-1)} \\
& =4.65 \mathrm{~m} .
\end{aligned}
$$

Furthermore,

$$
\begin{aligned}
S= & 3.05 \times\left[\frac{((11.25+8.06)+2 \times(6.77 /(2.37-1)))}{(2.37+1) \times 4.94}\right]^{1 /(2.37-1)} \\
& -\frac{2 \times(11.25-8.60) \cos (2 \theta)}{((11.25+8.60)+2(6.77 /(2.37-1)))(2.37-1)} \times 3.05 \\
& \times\left[\frac{((11.25+8.60)+2 \times(6.77 /(2.37-1)))}{(2.37+1) \times 4.94}\right]^{1 /(2.37-1)}, \\
S= & 3.05 \times\left[\frac{((11.25+8.60)+2 \times(6.77 /(2.37-1)))}{(2.37+1) \times 4.94}\right]^{1 /(2.37-1)} \\
& -\frac{((11.25+8.60)+2 \times(6.77 /(2.37-1)))(2.37-1)}{2 \times(11.25-8.60) \cos (2 \theta)} \times 3.05 \\
& \times\left[\frac{((11.25+8.60)+2 \times(6.77 /(2.37-1)))}{(2.37+1) \times 4.94}\right]^{1 /(2.37-1)} .
\end{aligned}
$$

$$
\begin{aligned}
\sigma_{r}^{p}= & \left(\frac{6.77}{2.37-1}\right)\left(\frac{1}{3.05}\right)^{2.37-1} \\
& \cdot\left(4.65^{2.37-1}+(2.37-1) \times 4.65^{2.37-2} f(\theta)\right)-\frac{6.77}{2.37-1}, \\
\sigma_{\theta}^{p}= & 2.37\left(\frac{6.77}{2.37-1}\right)\left(\frac{1}{3.05}\right)^{2.37-1} \\
& \cdot\left(4.65^{2.37-1}+(2.37-1) \times 4.65^{2.37-2} f(\theta)\right)-\frac{6.77}{2.37-1}, \\
\sigma_{y}^{p}= & \left(\frac{2.37+1}{2}\right)\left(\frac{6.77}{2.37-1}\right)\left(\frac{1}{3.05}\right)^{2.37-1} \\
& \cdot\left(4.65^{2.37-1}+(2.37-1) \times 4.65^{2.37-2} f(\theta)\right)-\frac{6.77}{2.37-1} .
\end{aligned}
$$

When $\theta=270^{\circ}$, it can be calculated that the radius of the plastic fracture zone range is $S=5.26 \mathrm{~m}$, the floor failure depth is $3.51 \mathrm{~m}$ (the distance from the center of the equivalent circular roadway to the actual floor is $1.75 \mathrm{~m}$ ), the boundary radial stress peak value in the floor plastic failure zone is $\sigma_{r}^{p}=5.02 \mathrm{MPa}$, the boundary shear stress peak value in the floor plastic failure zone is $\sigma_{\theta}^{p}=18.65 \mathrm{MPa}$, and the boundary axial stress peak value in the floor plastic failure zone is $\sigma_{y}^{p}=11.86 \mathrm{MPa}$.

\section{Conclusions}

(1) This paper takes the excavation roadway overall surrounding rock as the research object and uses the generalized plane strain problem and uniform strength theory to derive for the equations of the elastic-plastic zone stress together with the plastic fracture range of the roadway floor surrounding rock under three-directional in situ stresses.

(2) From the analysis of the influence of the stress environment to the roadway floor stability, it is concluded that the horizontal stress component of the roadway section should be avoided in accordance with the maximum stress component in the threedimensional stress state, and the support strength of the roadway floor should be increased when the initial vertical stress is greater than the maximum vertical stress, so as to ensure the safety and stability 
of the roadway floor surrounding rock. It is also important to pay attention to the three-dimensional stress state of the in situ stress to support the inclined roadway, according to the stress distribution of the surrounding rock and the distribution characteristics of the plastic fracture, and the spatial position relationship of the roadway should be combined to guide the roadway floor heave to ensure the safety and stability of the floor surrounding rock.

(3) From the mechanical analysis, the following conclusions are obtained: the range of the plastic failure zone range of roadway floor rock mass is $S=5.26 \mathrm{~m}$, the depth of the floor plastic failure is $3.51 \mathrm{~m}$, the boundary radial stress peak value in the floor plastic failure zone is $\sigma_{r}^{p}=5.02 \mathrm{MPa}$, the boundary shear stress peak value in the floor plastic failure zone is $\sigma_{\theta}^{p}=18.65 \mathrm{MPa}$, and the boundary axial stress peak value in the floor plastic failure zone is $\sigma_{y}^{p}=11.86 \mathrm{MPa}$. The above information provides a reliable mechanical reference for research on prevention and control technology of the roadway bottom drum.

\section{Data Availability}

The data can be obtained from the geological mechanics test report of the \#1 return airway in the S6 mining area of Changcun mine or from the corresponding author upon request.

\section{Conflicts of Interest}

The authors declare that they have no conflicts of interest.

\section{Acknowledgments}

This project was supported by the High School Science Research Project of the Inner Mongolia Autonomous Region (NJZY16158) and Inner Mongolia University of Science and Technology and Innovation Fund Project (2015QDL01).

\section{References}

[1] C. Carranza-Torres, "Dimensionless graphical representation of the exact elasto-plastic solution of a circular tunnel in a Mohr-Coulomb material subject to uniform far-field stresses," Rock Mechanics and Rock Engineering, vol. 36, no. 3, pp. 237-253, 2003.

[2] C. D. Martin, P. K. Kaiser, and D. R. McCreath, "Hoek-Brown parameters for predicting the depth of brittle failure around tunnels," Canadian Geotechnical Journal, vol. 36, no. 1, pp. 136-151, 1999.

[3] A. M. Nekouei and K. Ahangari, "Validation of Hoek-Brown failure criterion charts for rock slopes," International Journal of Mining Science and Technology, vol. 23, no. 6, pp. 805-808, 2013.

[4] M. Sari, "A simple approximation to estimate the HoekBrown parameter 'mi' for intact rocks," in Proceedings of the European Rock Mechanics Symposium on Rock Mechanics in Civil and Environmental Engineering, pp. 169-172, Lausanne, Switzerland, June 2010.
[5] R. H. Cao and H. Lin, "Experimental and numerical study of failure behavior and energy mechanics of rock-like materials containing multiple joints," Advances in Materials Science and Engineering, vol. 2017, Article ID 6460150, 17 pages, 2017.

[6] Y. Zhao, L. Zhang, W. Wang, J. Tang, H. Lin, and W. Wan, "Transient pulse test and Morphological analysis of single rock fractures," International Journal of Rock Mechanics and Mining Sciences, vol. 91, pp. 139-154, 2017.

[7] B. R. Chen, X. J. Zhao, X. T. Feng, H. B. Zhao, and S. Y. Wang, "Time dependent damage constitutive model for the marble in the Jinping II hydropower station in China," Bulletin of Engineering Geology and the Environment, vol. 73, no. 2, pp. 499-515, 2014.

[8] N. Gatelier, F. Pellet, and B. Loret, "Mechanical damage of an anisotropic porous rock in cyclic 561 triaxial experiments," International Journal of Rock Mechanics and Mining Sciences, vol. 39, no. 3, pp. 335-354, 2002.

[9] X. W. Li, J. H. Zhao, and Q. Y. Wang, "Maximum reduction in thickness in a single sheet forming pass based on unified strength theory," Applied Mechanics and Materials, vol. 159, pp. 151-155, 2012.

[10] Y. Zhao, L. Zhang, W. Wang, C. Pu, W. Wan, and J. Tang, "Cracking and stress-strain behavior of rock-like material containing two flaws under uniaxial compression," Rock Mechanics and Rock Engineering, vol. 49, no. 7, pp. 2665-2687, 2016.

[11] Q. Y. Ge, C. M. Li, F. L. Yang, and F. G. Qin, "The study of the axial compressive bearing capacity of core column with high strength concrete filled steel tube based on the twin shear unified strength theory," Advanced Materials Research, vol. 634-638, no. 1, pp. 2752-2756, 2013.

[12] Y. B. Wang, M. H. Yu, Y. Xiao, and L. S. Li, "Dynamic plastic response of a circular plate based on unified strength theory," International Journal of Impact Engineering, vol. 31, no. 1, pp. 25-40, 2005.

[13] X. Q. Wang, L. D. Yang, and W. H. Gao, "Calculation of bearing capacity about the strip foundation based on the twin shear unified strength theory," Tumu Gongcheng Xuebao, vol. 39, no. 1, pp. 79-82, 2006.

[14] X. J. Huang, J. X. Zhang, L. Yang, S. K. Yang, and X. L. Wang, "Elasto-plastic analysis of the surrounding rock mass in circular tunnel based on the generalized nonlinear unified strength theory," International Journal of Mining Science and Technology, vol. 26, no. 5, pp. 819-823, 2016.

[15] V. A. Kolupaev and H. Altenbach, "Einige überlegungen zur unified strength theory von Mao-Hong Yu," Forschuang im Ingenieurwesen, vol. 74, no. 3, pp. 135-166, 2010.

[16] J. L. Wen, W. L. Yang, Y. Liu, and C. X. Shu, "Rock burst and instability analysis for coal roadways based on unified strength theory," International Journal of Earth Sciences and Engineering, vol. 9, no. 5, pp. 2161-2165, 2016.

[17] Y. Zhao, Y. Wang, W. Wang, W. Wan, and J. Tang, "Modeling of non-linear rheological behavior of hard rock using triaxial rheological experiment," International Journal of Rock Mechanics and Mining Sciences, vol. 93, pp. 66-75, 2017.

[18] Y. L. Zhao, L. Y. Zhang, W. J. Wang, W. Wan, and W. H. Ma, "Separation of elasto-visco-plastic strains of rock and a nonlinear creep model," International Journal of Geomechanics, vol. 18, no. 1, 2018.

[19] Y. L. Zhao, L. Y. Zhang, W. J. Wang et al., "Creep behavior of intact and cracked limestone under multi-level loading and unloading cycles," Rock Mechanics and Rock Engineering, vol. 50, no. 6, pp. 1409-1424, 2017.

[20] M. H. Yu, W. Fan, A. L. Che, M. Yoshimine, and T. Iwatate, "Application of the unified strength theory in analyzing 
fracture strength," Key Engineering Materials, vol. 261-263, no. 1, pp. 111-116, 2004.

[21] M. H. Yu, "Linear and nonlinear unifiedstrength theory," Chinese Journal of Rock Mechanics and Engineering, vol. 26, no. 4, pp. 662-669, 2007.

[22] M. Vargonen, L. P. Huang, and Y. F. Shi, "Evaluating MohrCoulomb yield criterion for plastic flow in model metallic glasses," Journal of Non-Crystalline Solids, vol. 358, no. 24, pp. 3488-3494, 2012.

[23] M. K. Liao, Y. M. Lai, J. J. Yang, and S. Y. Li, "Experimental study and statistical theory of creep behavior of warm frozen silt," KSCE Journal of Civil Engineering, vol. 20, no. 6, pp. 2333-2344, 2016.

[24] Q. Zhang, S. L. Wang, X. R. Ge, and H. J. Wang, "Modified Mohr-Coulomb strength criterion considering rock mass intrinsic material strength factorization," Mining Science and Technology, vol. 20, no. 5, pp. 701-706, 2010.

[25] G. Moradi and A. Abbasnejad, "Experimental and numerical investigation of arching effect in sand using modified Mohr Coulomb," Geomechanics and Engineering, vol. 8, no. 6, pp. 829-844, 2015.

[26] Y. L. Zhao, J. Z. Tang, Y. Chen et al., "Hydromechanical coupling tests for mechanical and permeability characteristics of fractured limestone in complete stress-strain process," Environmental Earth Sciences, vol. 76, p. 24, 2017.

[27] L. Jiang, A. Sainoki, H. S. Mitri, N. Ma, H. Liu, and Z. Hao, "Influence of fracture-induced weakening on coal mine gateroad stability," International Journal of Rock Mechanics and Mining Sciences, vol. 88, pp. 307-317, 2016.

[28] Y. S. Zhao, Z. J. Feng, Z. C. Feng, D. Yang, and W. G. Liang, "THM (thermo-hydro-mechanical) coupled mathematical model of fractured media and numerical simulation of a 3D enhanced geothermal system at $573 \mathrm{~K}$ and buried depth 6000-7000 M," Energy, vol. 82, pp. 193-205, 2015.

[29] P. J. Lou, "New solution of elastic and plastic mechanics of surrounding rock considering strain softening," International Journal of Earth Sciences and Engineering, vol. 9, no. 5, pp. 2234-2240, 2016.

[30] A. Z. Zhou, P. M. Jiang, J. P. Xiao, F. W. Li, and W. Wang, "Elastic-plastic solution of stress-deformation distribution for double-linings circular rock tunnel (i): radial stress as the first principal stress," Journal of Mechanical Engineering Research and Developments, vol. 39, no. 4, pp. 8464-8853, 2016. 


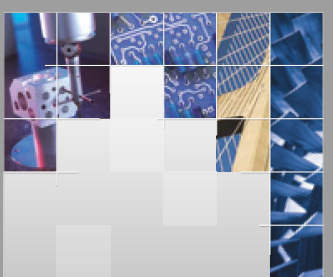

\section{Enfincering}
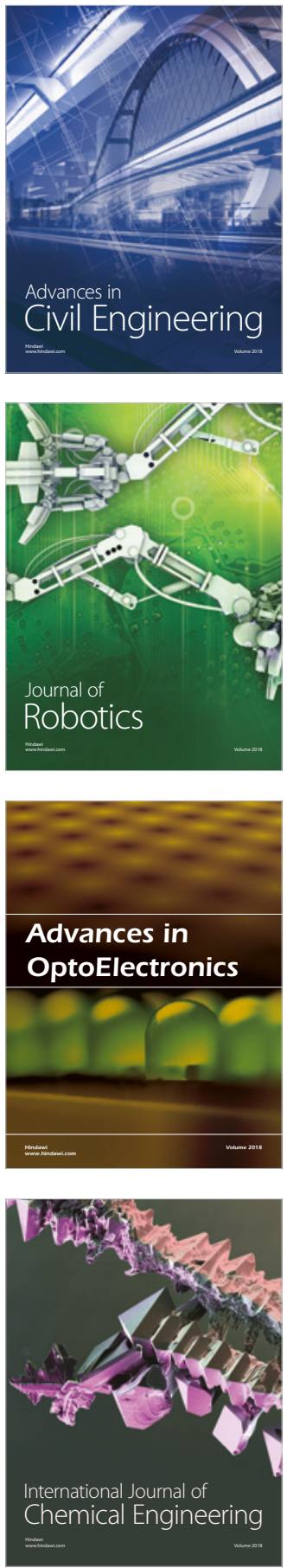

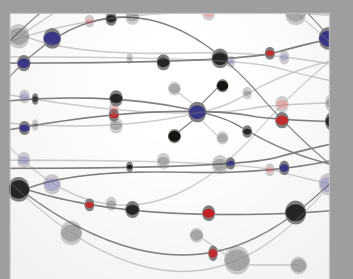

\section{Rotating \\ Machinery}

The Scientific World Journal

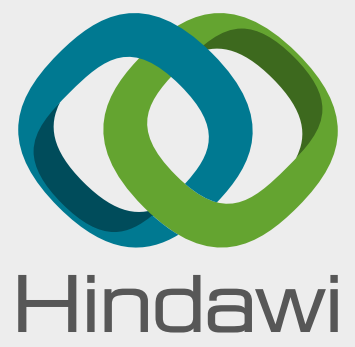

Submit your manuscripts at

www.hindawi.com
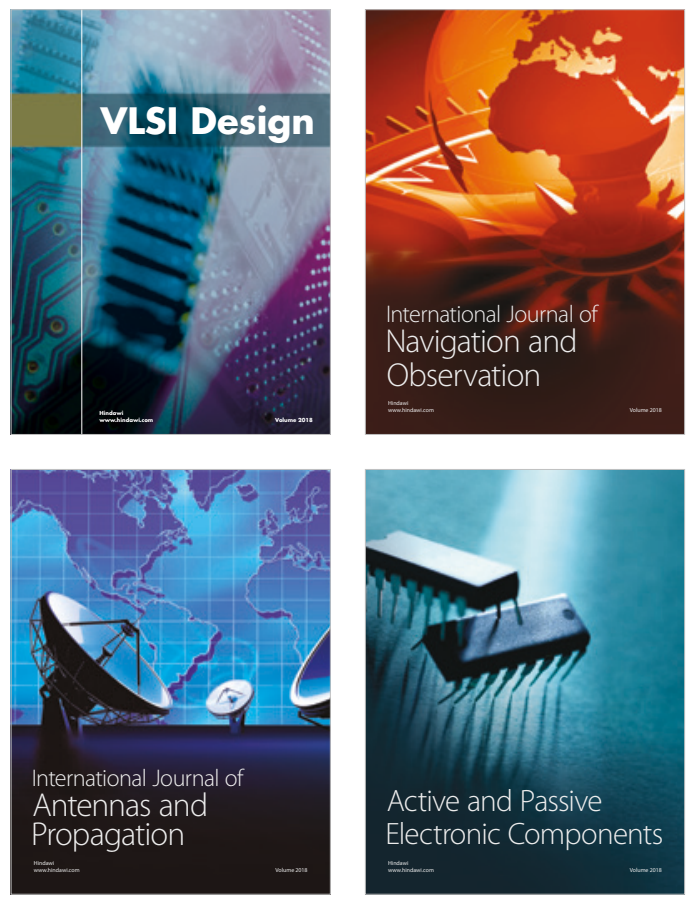
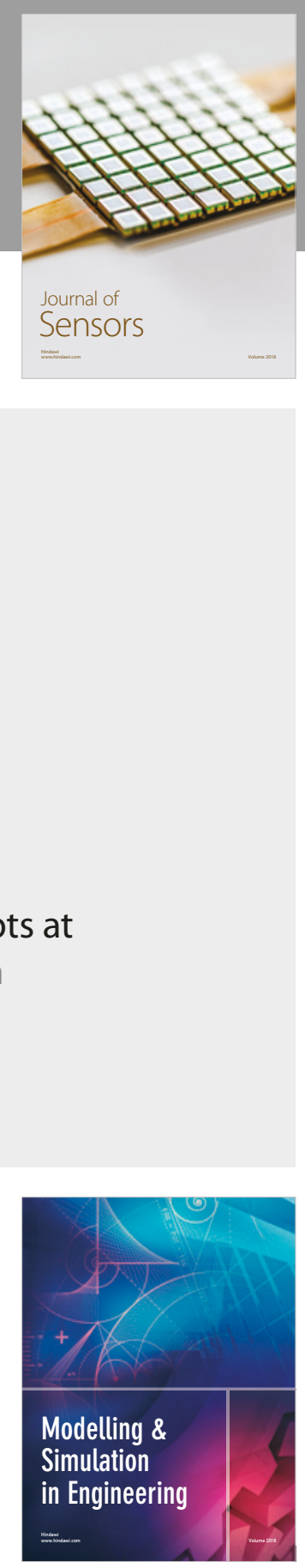

\section{Advances \\ Multimedia}
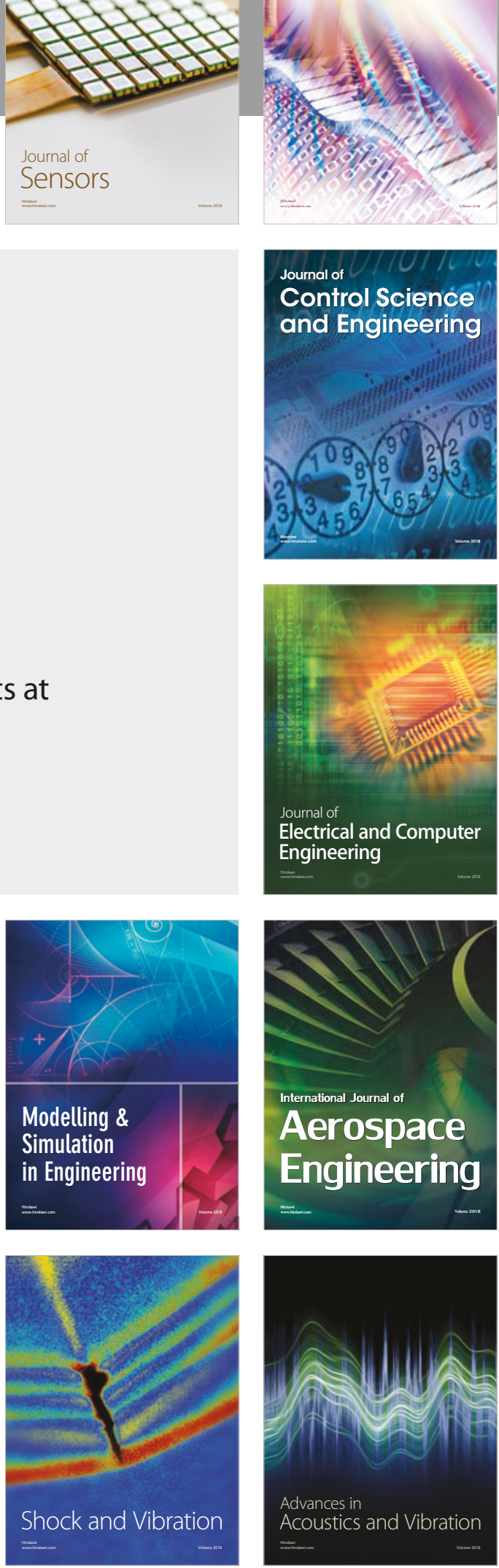